\title{
The effects of information on willingness to pay for animal welfare in dairy production: Application of nonhypothetical valuation mechanisms
}

\author{
L. Elbakidze ${ }^{\star 1}$ and R. M. Nayga Jr.† \\ *Department of Agricultural Economics and Rural Sociology, University of Idaho, 606 Rayburn St., Moscow 83844-2334 \\ †Department of Agricultural Economics and Agribusiness, University of Arkansas, 217 Agriculture Building, Fayetteville 72701
}

\begin{abstract}
The objective of this study was to examine consumer willingness to pay (WTP) for animal welfare in dairy production using nonhypothetical Vickrey auctions and open-ended choice experiments. Two hundred fifteen subjects participated in experimental sessions with 4 types of dairy products (humane animal care-labeled cheese and ice cream and conventional cheese and ice cream) and 4 valuation mechanisms. Information treatment, which included information about humane animal care principles in dairy production, was used to examine the effects of information on WTP. The results showed that participants, on average, were willing to pay extra for a scoop of humane animal care-labeled ice cream above the price of conventional ice cream. However, no premium WTP for humane animal carelabeled cheese was detected. Furthermore, provision of information only about humane animal care principles in dairy production, without corresponding information about conventional production practices, did not increase WTP for humane animal care-labeled products. Key words: willingness to pay, animal welfare
\end{abstract}

\section{INTRODUCTION}

In 2008, the Pew Charitable Trust and Johns Hopkins Bloomberg School of Public Health published a report (Pew Commission, 2008) on industrial farm animal production in which the present system of animal agriculture was judged to be unsustainable due to, among other things, "unacceptable risk to public health," damage to environment, and "unnecessary harm to the animals we raise for food." This report provoked a response from the American Veterinary Medical Association (2009) that criticized many of the findings in the original Pew report and argued that the report contained "significant flaws and major deviations from both science and reality." Ambiguities surround the is-

Received July 14, 2011.

Accepted November 14, 2011

${ }^{1}$ Corresponding author: lelbakidze@uidaho.edu sue of animal welfare even among the experts, and the role of science alone remains limited in identifying "appropriate" practices and definitions of animal welfare (von Keyserlingk et al., 2009).

The animal welfare issue has become a point of debate among the public as well as in political circles (Norwood and Lusk, 2009). On the one hand, proponents of animal welfare argue for improved mandatory standards for animal handling in agricultural production. On the other hand, agricultural producers and opponents of mandatory animal handling standards question the validity of assumptions behind and arguments for "improved" animal welfare. A major complication is the public good nature of the animal welfare issue, which reduces the economic efficiency of market-based solutions (Norwood and Lusk, 2009). Nevertheless, provision of information pertaining to ethical dimensions of production, including animal welfare, can have a major effect on demand for products with "desirable" but costly to observe attributes (Frank, 2006). For example, Kiesel et al. (2005) conclude that provision of additional positive information can increase consumption of the commodity that has a desirable but costly to observe characteristic. In this study, we investigate the effects of providing factual information about humane animal care-labeled products on willingness to pay (WTP) for such products when animal welfare-related information about conventional product is not available.

Willingness to pay for food products obtained using surveys, hypothetical choice experiments, and consumer sensory evaluation techniques has been questioned because stated responses in hypothetical contexts may differ from consumers' actual behavior and true WTP (Cummings et al., 1995; List and Shogren, 1998; Lusk and Schroeder, 2004). Consequently, interest is increasing in using nonhypothetical experimental auctions (Alfnes and Rickertsen, 2003; Rousu et al., 2004; Corrigan and Rousu, 2006) and nonhypothetical choice experiments (Alfnes et al., 2006; Corrigan et al., 2009) to estimate WTP. Most of the studies that address consumer WTP for animal welfare in agricultural production rely on survey-based hypothetical choice experiments (Lusk et al., 2007; Tonsor et al., 2009; Olynk et al., 2010). Only 
a few studies (Napolitano et al., 2008, 2010; Carlucci et al., 2009) have used nonhypothetical auctions to measure WTP for higher animal welfare standards in dairy production. Our study differs from these latter studies in several noteworthy aspects. First, in addition to using 3 types of nonhypothetical experimental auction techniques, we also used a nonhypothetical choice experiment to further validate the robustness of the findings. Second, we used 2 types of products, cheese and ice cream, to examine potential differences across products. Third, we examined WTP for more than one unit of each product.

In this study, we estimated the WTP for humane animal care-labeled dairy products using nonhypothetical uniform price auctions and nonhypothetical choice experiments. Our objective was to examine how consumers respond to provision of information about what types of practices constitute humane animal care in dairy production. The information provided was designed to be neutral in the sense that the information treatment was not intended to intentionally affect, in either direction, participant attitudes toward humane animal care in agricultural production.

\section{MATERIALS AND METHODS}

\section{Experimental Design}

Four products, humane animal care-labeled and conventional cheese and ice cream, were used in this study. Conventional and animal welfare products were identical except for the labels identifying them as conventional or humane animal care certified. Each cheese was a 21-g semisoft cheese ball covered in wax. Ice cream was auctioned in increments of a standard scoop served in a plastic cup. Up to 5 units of cheese and up to 5 units of ice cream were offered to subjects.

Four valuation mechanisms were used in this study to check for robustness of the results: second- and random Nth-price Vickrey auctions (List and Shogren, 1999; Shogren et al., 2001; Rousu et al., 2004), incremental second-price Vickrey auction (Rousu et al., 2008), and open-ended choice experiment (OECE; Corrigan et al., 2009). Each session included 3 practice rounds followed by 5 real rounds.

Participants in second- and random Nth-price auctions submitted bids for $1,2,3,4$, and 5 units of animal welfare cheese and animal welfare ice cream in each of the 5 rounds. In the incremental second-price auctions, the number of animal welfare cheese and ice cream products auctioned was incrementally increased from 1 to 5 across rounds. The binding animal welfare product and the binding quantity were randomly selected (after each round in the case of second-price and random $N$ th- price auctions, and at the end of 5 rounds in the case of incremental auction). Identification numbers and bids of the winner(s) were displayed in the room following each round. The participants were told that only the winners would be expected to purchase the binding quantity of the binding product at the binding price. Participants were also informed that although they would be bidding only for humane animal care-labeled products, the conventional cheese and ice cream were available for purchase at the end of the session from the experimenter at prices equal to those at the nearest grocery store ( $\$ 0.50$ for a unit of cheese and $\$ 0.25$ for a scoop of ice cream).

In the OECE sessions, the participants indicated the number of animal welfare products that they would be willing to purchase at different price scenarios. Prices of conventional products were fixed at the same levels as in the auctions. The binding animal welfare product and the binding price scenario were randomly selected after each round. Quantities of the binding product indicated by each participant under the binding price scenario were displayed at the front of the room following each round. After 5 rounds, the binding round was randomly selected. Participants were aware that each of them would be expected to purchase the number of binding products that they indicated for the binding price scenario in the binding round.

\section{Information Treatment}

Each of the 4 valuation mechanisms included sessions where participants were informed about principles of humane animal care practices in dairy production, and sessions where the participants were not given any information about dairy production practices. For the informed treatment sessions, a 1-page information sheet (available from authors upon request) was compiled, summarizing the guidelines from the FAO (2008) and standards made public by Humane Farm Animal Care (2004). After the practice rounds, the experimenter read the information aloud and the participants were asked to read along. The information page stated that the humane animal case principles in dairy production included the following: access to clean water; clean feeding equipment; ability to engage in natural behaviors; no weaning before 5 weeks of age; appropriate milking parlor hygiene; bedded stalls to the minimum depth of 3 inches; rapid diagnosis and treatment of sick animals; access to shaded area during hot summer conditions; appropriate thermal environment and adequate ventilation; access to exercise areas for at least $4-5 \mathrm{~h}$ per day; nutritious diet without antibiotics (except for the purpose of disease treatment), hormones, or mammalian-derived protein sources (with the exception of milk 
products); no excessive mud causing cattle difficulty walking to and from feeding and watering areas; ample loafing space $40-50 \mathrm{sq}$. ft./adult cow in semi arid conditions and 20-40 sq. ft./head of roofed area in cooler climates; ample space in stalls to allow lying down without risk of being stepped on or kicked by other cows; no continuous confinement, except for the purposes of marking, washing, weighing, cleaning, milking, loading, or unless directed by the veterinarian; benign handling aids that do not cause pain (no electric prods except when animal or human safety is in jeopardy); and knowledge and understanding of humane animal care guidelines by all stockpersons and managers.

\section{Data}

The participants of the experiments were recruited from 2 adjacent towns (Pullman, WA, and Moscow, ID) and the experiments took place on the campus of the University of Idaho in Moscow. The participants were recruited through a variety of means, including fliers posted on university campuses and city public gathering points, newspaper advertisements, and e-mail lists. The participants were given $\$ 30$ each as compensation for participation. The subjects were free to use none, some, or all of this money to bid and pay for the items during the experiment.

Table 1 provides summary statistics for the data. Two hundred fifteen participants were included in this study, and approximately $56 \%$ of participants were undergraduate college students. The high proportion of undergraduate students in the sample may raise questions about extrapolation to the general population. However, Depositario et al. (2009) found no significant differences in valuation estimates for food products between college students and the general population. Average age in our sample was $28 \mathrm{yr}$, with standard deviation of 12 and a range from 18 to 68. Approximately $28 \%$ of the participants self-identified as coming from a farming background. The data also included an estimate of the participants' level of comfort in the experimental design and the information provided in the experiment. At the end of each session, the participants were asked to provide their level of trust or confidence in the authenticity and credibility of the experimental design (trust score), measured from 1 (lowest level of trust) to 5 (highest level of trust). This measure was included to gauge potential skepticism of the participants. The participants were assured that their responses to the survey, including the trust score and the bids, could not be linked to their identities because the survey did not ask for their names. Instead, the survey included only participant ID, whereas names were included only on the participation consent form collected separately.

\section{RESULTS AND DISCUSSION}

Table 2 shows the WTP estimates for 1 unit of product across informed and uninformed treatment groups in each valuation mechanism across 5 rounds. Willingness to pay estimated in auction mechanisms corresponded to the bids submitted by the participants. However, because in the OECE the participants indicated number of units that they would be willing to purchase at various price levels, WTP in OECE was calculated as the highest price at which the subject indicated a positive quantity, as was done in Corrigan et al. (2009).

The results showed that, on average, the participants were willing to pay premium price for only 1 scoop of humane animal care-labeled ice cream. In case of more than 1 scoop of ice cream, the participants were not willing to pay more per scoop of humane animal carelabeled ice cream than the reference price of conventional ice cream. In addition, average premium WTP for one scoop of humane animal care-labeled ice cream was more pronounced in OECE than in the auction mechanisms. For cheese, the participants, on average, were not willing to pay a greater price for even 1 unit of humane animal care-labeled cheese compared with the price of conventional cheese.

The cause of this divergence in WTP premium prices for humane animal care between 1 unit of ice cream and 1 unit of cheese is not clear. We offer 2 potential explanations, although other explanations might be possible. One is the functional difference between cheese and ice cream. Cheese is a relatively storable product, whereas ice cream is an immediate consumption product unless frozen soon after purchase. In the case of our experiments, access to freezers was most likely not available for most of the participants soon enough following the experiments (the experiments were conducted around lunchtime). Therefore, if the participants purchased ice cream, they would need to consume it soon after the experiment. The participants may not have been willing to consume both cheese and ice cream at one time. In such a case, if a participant purchased both products then (s)he would have to keep the cheese for later consumption. It may be that the participants did not want to deal with carrying cheese with them until returning home at the end of the day. Given that the participants might have been more willing to consume ice cream than cheese on the spot, and that they may have been not inclined to consume both immediately and not willing to carry cheese home, they may have submitted lower bids for cheese than if the experiment were conducted just using cheese. The second possible reason for the inconsistency between cheese and ice cream may be bid anchoring. The participants may 
Table 1. Summary statistics for 4 valuation mechanisms

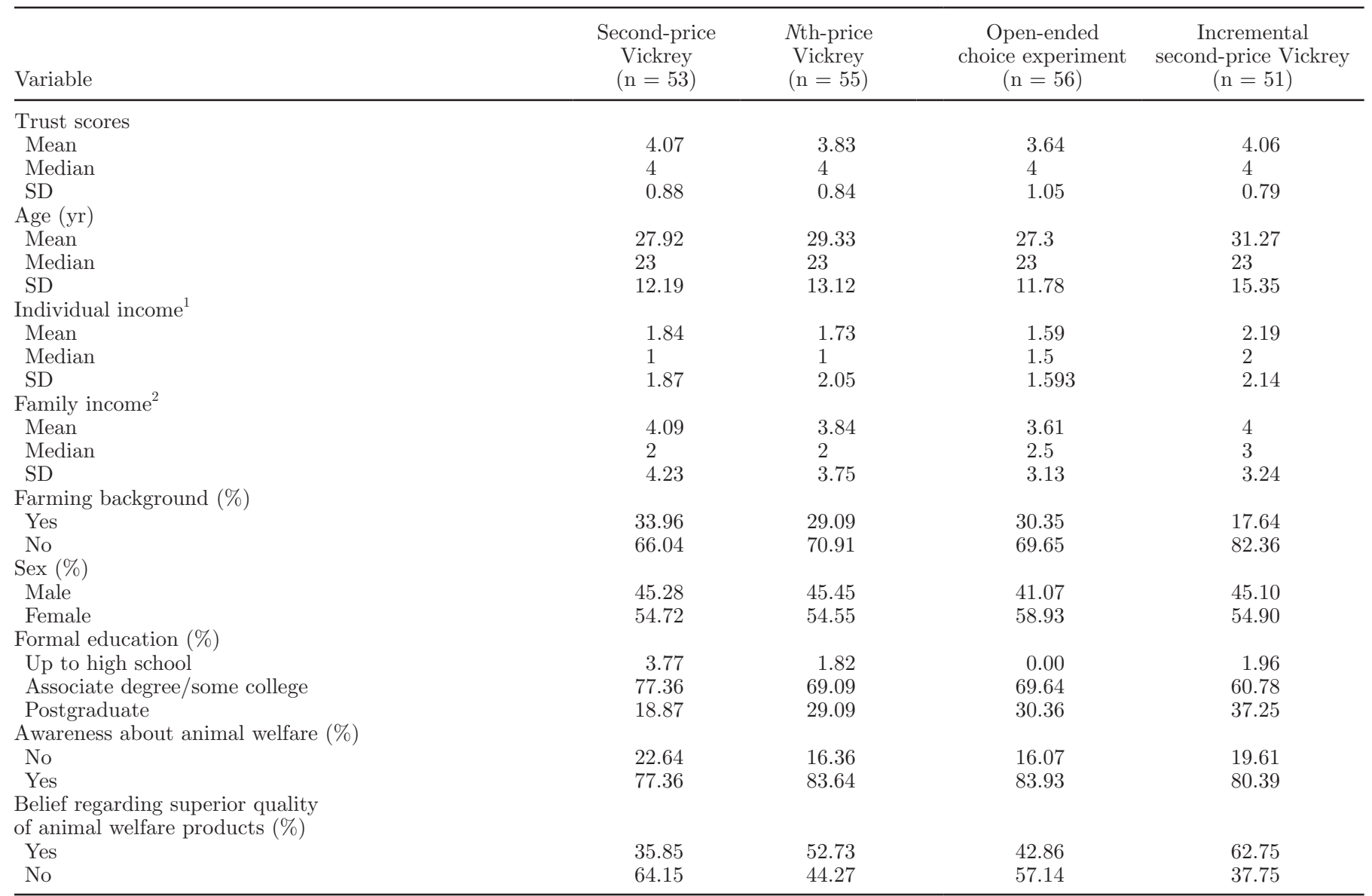

${ }^{1}$ Individual monthly income was reported and coded in intervals: $1=<\$ 499,2=\$ 500-\$ 999,3=\$ 1,000-\$ 1,999,4=\$ 2,000-\$ 2,999$, and so on. ${ }^{2}$ Family monthly income was reported and coded in intervals: $1=<\$ 999,2=\$ 1,000-\$ 1,999,3=\$ 2,000-\$ 2,999,4=\$ 3,000-\$ 3,999$, and so on.

have anchored their bids on the lower of the 2 reference prices for conventional products (i.e., ice cream product).

Higher WTP in OECE then in auction mechanisms was detected for cheese as well as ice cream. This is not surprising because the lowest price scenarios in OECE were $\$ 0.10$ for ice cream and $\$ 0.25$ for cheese. On the other hand, the Vickrey auctions have no preset minimums on disclosed WTP values. This may imply that the OECE can suffer from starting point bias similar to that occurring in contingent valuation studies that use a payment card elicitation mechanism. If so, then WTP estimates obtained from choice experiments could differ from those obtained from auction mechanisms as in this study.

Table 2 also shows that in all mechanisms except for the random Nth-price and incremental second-price auctions for cheese, mean WTP for uninformed groups was higher than corresponding mean WTP from informed groups. A possible explanation for this is the one-sided nature of the information treatment. Subjects were only exposed to the information about what types of practices are consistent with humane animal care in dairy production. No information was provided about what types of practices constitute conventional dairy production or how the two differ. If participants in the information treatment group were not familiar with conventional dairy production practices, then they may have the impression that animal-friendly dairy production practices described in the information treatment page may not be very different from conventional dairy production practices. In such a case, the subjects may not be willing to pay a premium price for animal welfare-labeled products if they do not believe that the animal welfare production practices and conventional production practices differ sufficiently to justify the premium price. In fact, some participants from the informed groups might be willing to pay less for animal welfare products as a demonstration of protest against potentially misleading labeling, advertising, or marketing if they believe that the conventional and animal welfare production practices do not differ enough in 
Table 2. Willingness to pay (WTP) for 1 unit in auctions and open-ended choice experiment (OECE) in consumers informed and not informed about animal welfare practices ${ }^{1}$

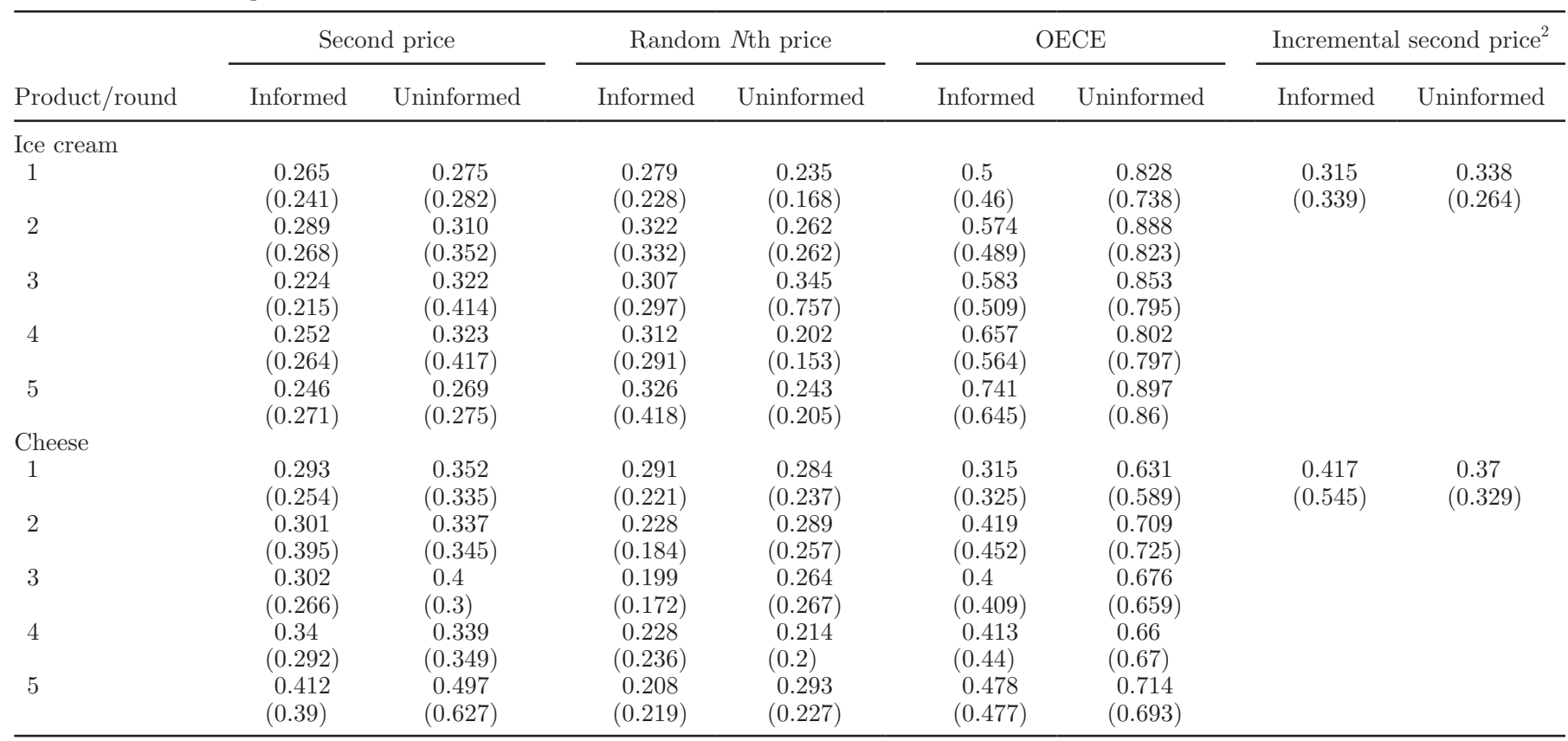

${ }^{1}$ Standard errors are in parentheses.

${ }^{2}$ In the incremental second price auction, the round order also corresponded to the amount of products being auctioned; thus, we only report the results from the first round.

terms of animal welfare in production to justify the labeling differentiation.

The Shapiro-Wilk tests (Royston, 1982) rejected the hypothesis of normality of bid distributions for various quantities of cheese and ice cream across informed and uninformed groups in all instances except for bids for 2,3 , and 4 units of cheese in incremental auctions. Using Wilcoxon's nonparametric rank-sum test (Wilcoxon 1945), we performed pair-wise comparisons of bids from corresponding informed and uninformed groups. Table 3 reports Mann-Whitney (MW) statistics with $P$-values in parentheses, as well as the probabilities (in italics) that a randomly picked bid from an uninformed group is greater than a randomly picked bid from a corresponding informed group using data from all rounds. For example, in the second price auction, the Mann-Whitney statistic (0.36) and the $P$-value $(0.72)$ indicated that the distributions of bids for 1 scoop of ice cream from uninformed participants was not statistically different from bids for 1 scoop of ice cream from informed participants. The probability that a randomly drawn bid for 1 scoop of ice cream from the pool of bids submitted by the uninformed bidders was greater than a randomly drawn corresponding bid submitted by informed participants was 0.51. Interpretation of values for OECE was similar except that in this case we were comparing submitted product quantities that the subjects were willing to buy at given price levels rather than WTP values, as in the auctions. Overall, the results in Table 3 provided no evidence that informed participants might be willing to pay more for animal welfare products than uninformed participants.

Figure 1 shows box plots of average per unit WTP values across all rounds and quantities for the auctions and OECEs. Box plots are presented for informed and uninformed treatment groups as well as across participants who self-identified as coming or not coming from a farming background. Figure 1 shows medians (bold horizontal line), 25th and 75th percentiles (boxes), upper and lower adjacent values (whiskers; Tukey, 1977), and observations that fell beyond the adjacent values. The data indicate that WTP estimates from the OECE tended to be greater than WTP from the auctions. This was confirmed with Wilcoxon's rank-sum test of WTP from OECE against WTP from auctions [MW $($ ice cream $)=-15.9, \mathrm{MW}($ cheese $)=-8.4, P$-value $=$ $0.000)$, where the probability that a randomly drawn WTP from auction was greater than a randomly drawn WTP from OECE is 0.214 for ice cream and 0.35 for cheese. This result also holds when comparing OECE with the individual auction mechanisms.

Overall, the test of whether WTP of individuals coming from a farming background was different from WTP of those not coming from a farming background indicated no statistically significant difference at 5\% level for ice cream $(\mathrm{MW}=1.81, P$-value 0.07$)$, with 
Table 3. Wilcoxon test statistics for informed and uninformed groups ${ }^{1}$

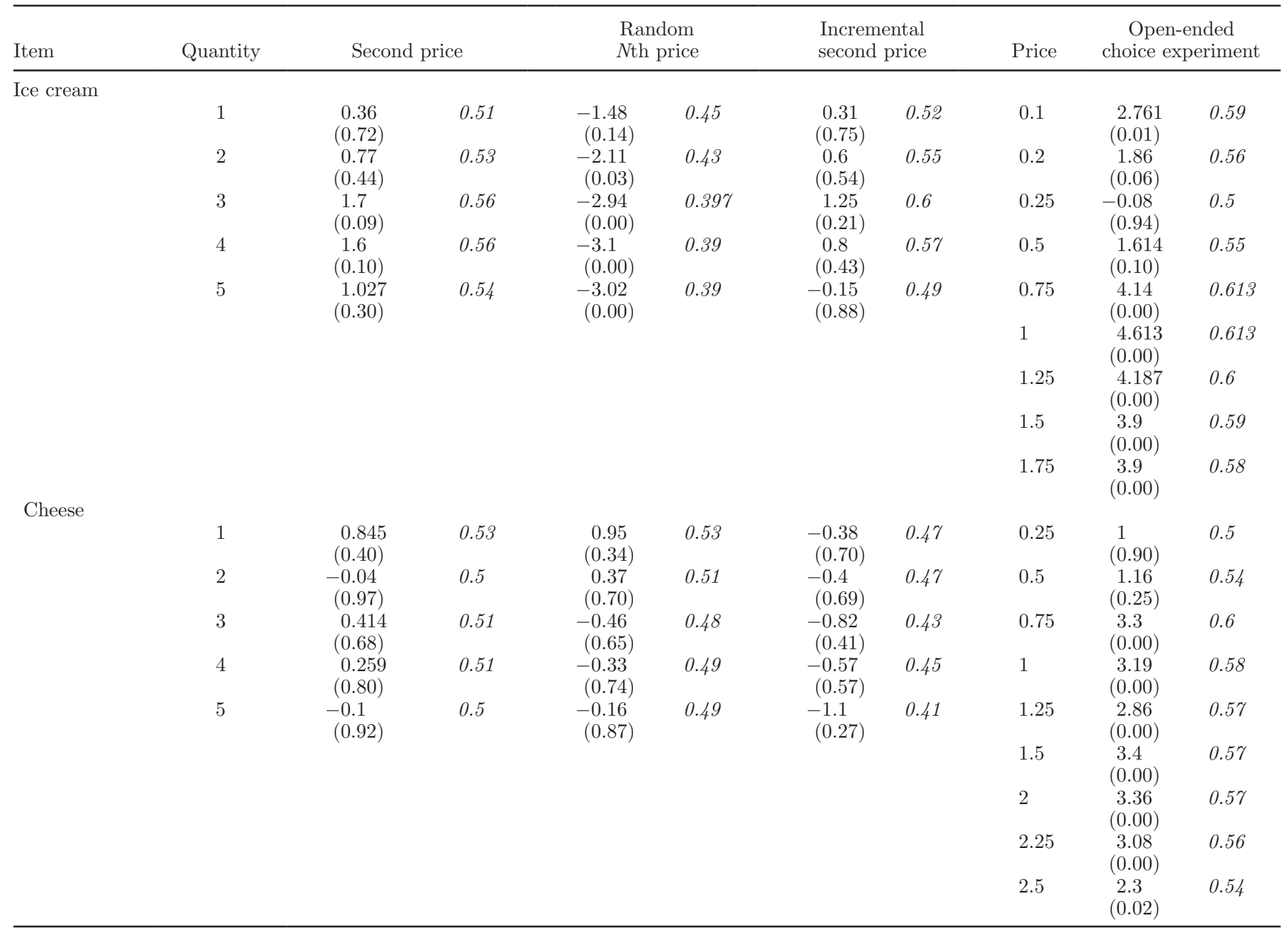

${ }^{1}$ Values in parenthesis are $P$-values, and values in italics are probabilities that a bid from uninformed group is greater than a bid from corresponding informed group. For auctions, Mann-Whitney (MW) statistics pertain to willingness-to-pay bids submitted by the informed and uninformed participants in each quantity scenario. For open-ended choice experiments, MW statistics pertain to quantities submitted by informed and uninformed participants in each price scenario.

0.52 probability that a participant with no farming background would pay more than a participant with a farming background. However, for cheese, the test indicated that the WTP of participants coming from a farming background tended to be higher than that of participants not coming from a farming background $(\mathrm{MW}=-3.4, P$-value $=0.0006)$. The probability that the WTP of a nonfarming background participant was greater than that of a farming background participant was 0.42 . This suggests that the low average WTP per unit, at least for cheese in auctions (Table 2), may not be attributed to the study being conducted on a landgrant university campus.

Because the sample of participants included a significant number of undergraduate students (120 out of 215), we used Wilcoxon's nonparametric test to determine if the undergraduate students' WTP differed from that of those who were not undergraduate students. The test indicated that the average per unit WTP across all quantity scenarios for ice cream was statistically higher among nonundergraduates than among undergraduate students $(z=7.115, P$-value $=0)$. The probability that a randomly picked per unit average WTP of a nonundergraduate was higher than a randomly picked average per unit WTP of an undergraduate was 0.57. Similar results were found for cheese $(z=6.9, P$-value $=0$, probability $=0.57)$. Mean average per unit WTP for ice cream for nonundergraduates and undergraduates was $\$ 0.31$ and $\$ 0.24$, respectively. Similarly, for cheese, the mean average WTP among nonundergraduates and undergraduates was $\$ 0.30$ and $\$ 0.26$, respectively. This indicated that our estimates maybe biased downward 


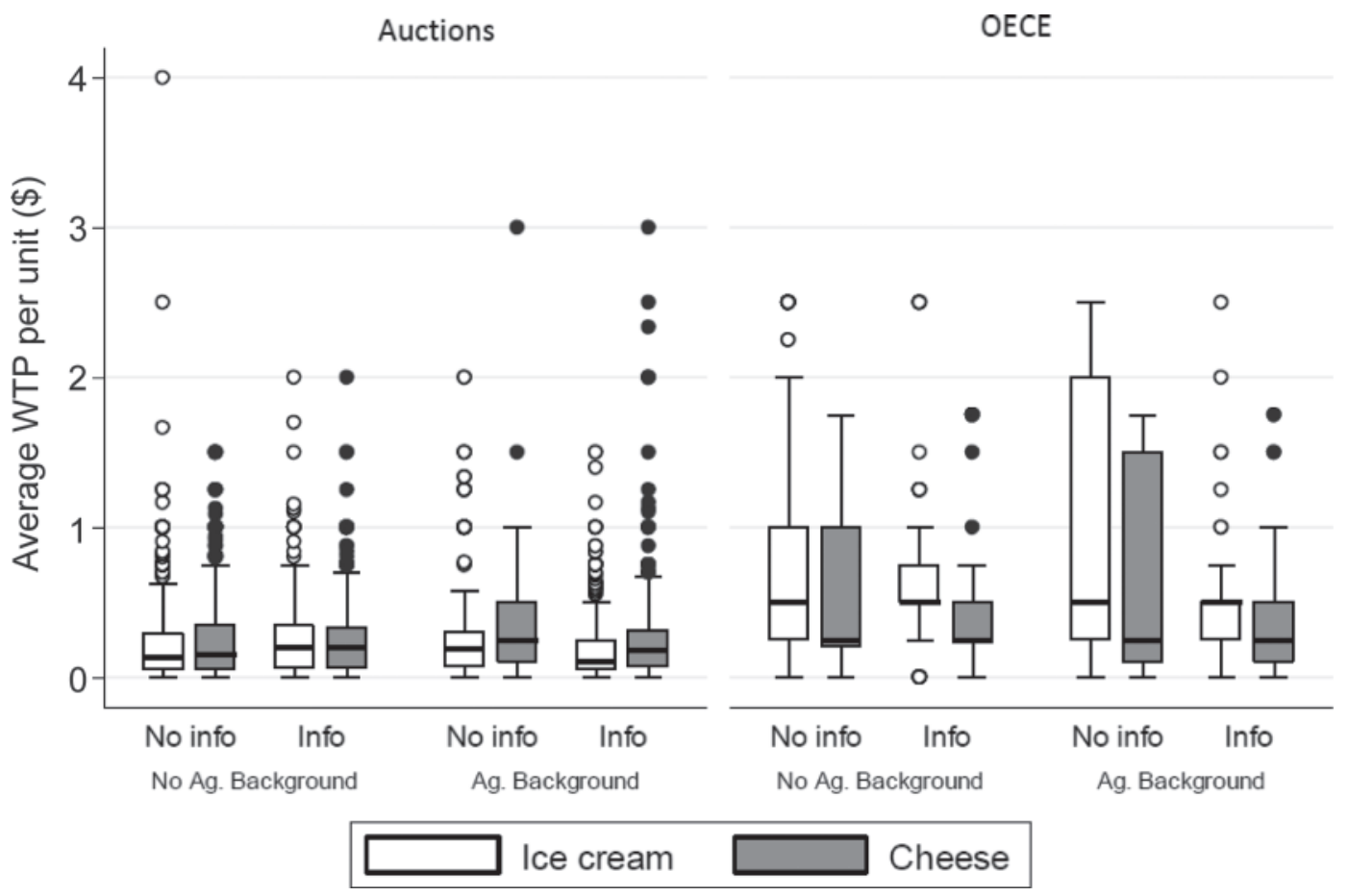

Figure 1. Box plots of average per unit willingness to pay (WTP) for cheese and ice cream across informed (info) and uninformed (no info) groups, agricultural and nonagricultural backgrounds, and valuation mechanisms (auction or open-ended choice experiment, OECE).

because of the significant number of undergraduates in the sample, or biased upward because of the significant number of nonundergraduate students (e.g., faculty and staff) in the sample

Similar to the results in Napolitano et al. (2008), our results indicated that consumers might be willing to pay a premium price for some humane animal care-labeled dairy products, specifically ice cream. Although the estimated magnitude of WTP across the experimental mechanisms used in this study varied, all mechanisms indicated that the consumers were, on average, willing to pay a higher price for a scoop of humane animal care-labeled ice cream than for conventional ice cream. However, participants were willing to pay a premium price for only one scoop of humane animal care-labeled ice cream and not for more. Subjects were not willing to pay a premium price for humane animal care-labeled cheese at any quantity. Consistent with diminishing marginal benefits of consuming additional units of food products, average per unit WTP for both products decreased as quantity increased.

Unlike the results of Napolitano et al. (2008), our results generally suggested that providing information about humane animal care practices in dairy production, at least the way it was provided in this study, did not significantly increase WTP for such dairy products. Provision of only information about humane animal care principles without provision of corresponding information about conventional production practices did not have a positive effect on WTP in most cases. In fact, in some cases, it could have a negative effect. This effect may be due to the inability of partially informed subjects to directly contrast the described unobservable attributes of the humane animal care products with the not-described unobservable attributes of conventional products. This could create the impression that the 2 products are not sufficiently different in terms of humane animal care practices to justify the premium price. Humane animal care production principles may appear to be normal and not very different from conventional production practices to consumers who are not familiar with standard production practices. This implies that informing consumers about humane animal care practices alone, as a tool to differentiate products and increase competitiveness (Napolitano et al. 2008), will probably not result in increased WTP unless corresponding information is provided about conventional practices. The WTP values in our study could differ if this reference information about conventional dairy production was provided. Therefore, one may speculate that given the results of this study, successful marketing of humane animal care-labeled dairy products may require educating consumers about potential differences between conventional and animal-friendly production 
practices in the dairy industry. If such differences were sufficiently significant and consumers were aware of these differences, WTP for humane animal care-labeled dairy products might be more pronounced than what was found in this study. This topic would be interesting to examine further in future studies.

\section{CONCLUSIONS}

In general, we did not find strong evidence that participants were willing to pay premium prices for humane animal care-labeled dairy products. If consumer WTP is not sufficiently high to cover the additional marginal costs of production associated with humane animal care requirements, then dairy producers are not likely to benefit from producing such products. However, the fact that we found some evidence of willingness to pay a premium price for one scoop of humane animal care ice cream suggests the need for further research before a final recommendation can be made about market potential for humane animal care-labeled dairy products. In general, provision of information about humane animal care practices alone, without provision of information about conventional practices, did not increase WTP. A couple of limitations need to be mentioned. The composition of the sample used in this study presents a limitation for the purposes of generalizing the results to the whole population. Participants were recruited in a predominantly college-oriented area, which is not representative of general population. Unlike Depositario et al. (2009), we found that undergraduate students' WTP estimates for humane animal care-labeled ice cream and cheese obtained via experimental auctions and choice experiments differed statistically from WTP of nonundergraduates. Furthermore, because the nonundergraduate category in our sample included graduate students, faculty, university staff, as well as nonuniversity-affiliated city residents, it was not possible to make a meaningful comparison between our nonundergraduate group and general population. In addition, methods used for recruiting participants, although typical for nonhypothetical experimental studies of WTP, may have affected the results in a nonrandom manner. These limitations are typical for WTP studies conducted on university campus sites and should be taken into account when attempting to extrapolate the results to the whole population. Another potential limitation of this study was the possible bid anchoring by the participants, which may have contributed to low estimates of WTP for humane animal care-labeled cheese, the more expensive of the 2 products considered in this study. Although inclusion of multiple products in studies of WTP for such unobservable attributes as animal welfare in agricultural production is a valuable factor in verifying robustness of findings, we suggest that the use of multiple products in experimental auctions be revisited in future studies to examine in more detail the effects of potential bid anchoring.

\section{ACKNOWLEDGMENTS}

Research was supported by federal funds provided by US Department of Agriculture's Federal State Marketing Improvement Program.

\section{REFERENCES}

Alfnes, F., A. G. Guttormsen, G. Steine, and K. Kolstad. 2006. Consumers' willingness to pay for the color of salmon: A choice experiment with real economic incentives. Am. J. Agric. Econ. 88:1050-1061.

Alfnes, F., and K. Rickertsen. 2003. European consumer's willingness to pay for U.S. beef in experimental auction markets. Am. J. Agric. Econ. 85:396-405.

American Veterinary Medical Association. 2009. Response to the final report of the Pew Commission on industrial farm animal production. Accessed May 23, 2010. http://www.avma.org/advocacy/ PEWresponse/.

Carlucci, A., E. Monteleone, A. Braghieri, and F. Napolitano. 2009 Mapping the effect of information about animal welfare on consumer liking and willingness to pay for yogurt. J. Sens. Stud. 24:712-730.

Corrigan, J. R., D. P. T. Depositario, R. M. Nayga Jr., X. Wu, and T. P. Laude. 2009. Comparing open-ended choice experiments and experimental auctions: An application to golden rice. Am. J. Agric. Econ. 91:837-853.

Corrigan, R. J., and M. C. Rousu. 2006. Posted prices and bid affiliation: Evidence from experimental auctions. Am. J. Agric. Econ. 88:1078-1090.

Cummings, R. G., G. W. Harrison, and E. E. Rutstrom. 1995. Homegrown values and hypothetical surveys: Is the dichotomous choice approach incentive compatible? Am. Econ. Rev. 85:260-266.

Depositario, D. P. T., R. M. Nayga Jr., X. Wu, and T. P. Laude. 2009. Should students be used as subjects in experimental auctions? Econ. Lett. 102:122-124.

Food and Agriculture Organization (FAO). 2008. National dairy animal well-being initiative: Principles and guidelines for dairy animal well-being. Accessed Sep. 10, 2009. http://www.fao.org/fileadmin/user_upload/animalwelfare/Dairywellbeing_Guidelines.pdf.

Frank, J. 2006. Process attributes of goods, ethical considerations and implications for animal products. Ecol. Econ. 58:538-547.

Humane Farm Animal Care. 2004. Humane farm animal care: Animal care standards: Dairy cows. Accessed Sep. 10, 2009. http:// www.certifiedhumane.org/uploads/pdf/Standards/English/Microsoft \%20Word\%20-\%20Std04.Dairy.3A.pdf.

Kiesel, K., D. Buschena, and V. Smith. 2005. Do voluntary biotechnology labels matter to the consumer? Evidence from the fluid milk market. Am. J. Agric. Econ. 87:378-392.

List, J. A., and J. F. Shogren. 1998. Calibration of the differences between actual and hypothetical valuations in a field experiment. J. Econ. Behav. Organ. 37:193-205.

List, J. A., and J. F. Shogren. 1999. Price information and bidding behavior in repeated second-price auctions. Am. J. Agric. Econ. 81:942-949.

Lusk, J. L., T. Nilsson, and K. Foster. 2007. Public preferences and private choices: Effect of altruism and free riding on demand for environmentally certified pork. Environ. Resour. Econ. 36:499521 .

Lusk, J. L., and T. C. Schroeder. 2004. Are choice experiments incentive compatible? A test with quality differentiated steaks. Am. J. Agric. Econ. 86:467-482. 
Napolitano, F., C. Pacelli, A. Girolami, and A. Braghieri. 2008. Effect of information about animal welfare on consumer willingness to pay for yogurt. J. Dairy Sci. 91:910-917.

Napolitano, F., A. Braghieri, E. Piasentier, S. Favotto, S. Naspetti, and R. Zanoli. 2010. Cheese liking and consumer willingness to pay as affected by information about organic production. J. Dairy Res. 77:280-286.

Norwood, B. F., and J. L. Lusk. 2009. The farm animal welfare debate. Accessed Jan. 9, 2012. http://www.choicesmagazine.org/ magazine/article.php?article $=89$.

Olynk, N. J., G. T. Tonsor, and C. A. Wolf. 2010. Consumer willingness to pay for livestock credence attribute claim verification. J. Agric. Res. Econ. 35:261-280.

Pew Commission. 2008. Putting meat on the table: Industrial farm animal production in America. Accessed May 2010. http://www. ncifap.org/.

Rousu, M. C., R. H. Beach, and J. R. Corrigan. 2008. The effects of selling complements and substitutes on consumer willingness to pay: Evidence from a laboratory experiment. Can. J. Agric. Econ. 56:179-194.
Rousu, M. C., W. E. Huffman, J. F. Shogren, and A. Tegene. 2004. Estimating the public value of conflicting information: The case of genetically modified foods. Land Econ. 80:125-135.

Royston, P. 1982. An extension of Shapiro and Wilks's W test for normality to large samples. Appl. Stat. 31:115-124.

Shogren, F. J., M. Margolisa, C. Koob, and J. A. List. 2001. A random Nth-price auction. J. Econ. Behav. Organ. 46:409-421.

Tonsor, G., N. Olynk, and C. Wolf. 2009. Consumer preferences for animal welfare attributes: The case of gestation crates. J. Agric. Appl. Econ. 41:713-730.

Tukey, J. W. 1977. Exploratory Data Analysis. Addison-Wesley, Reading, MA.

von Keyserlingk, M. A. G., J. Rushen, A. M. de Passillé, and D. M. Weary. 2009. Invited review: The welfare of dairy cattle-Key concepts and the role of science. J. Dairy Sci. 92:4101-4111.

Wilcoxon, F. 1945. Individual comparisons by ranking methods. Biometrics $1: 80-83$. 